the conclusion drawn by me in NATURE of October 22, that Michelson and Morley's repetition of the experiment, when correctly interpreted, is in close agreement with the predictions of the principle of relativity. This being so, it may be worth while to direct attention to certain facts in connection with that experiment which render it quite inconclusive.

(I) On the ground of an experimental device for estimating the pressure gradient at different points of the tube, Michelson and Morley assume that the velocity along the axis is equal to $1 \cdot 16_{5}$ times the mean velocity. This is in sharp contradiction with the theory of the flow of liquid in a tube which shows that the axial velocity is twice the mean.

(2) The beam of light which traverses the tubes appears from the figures given to occupy a considerable fraction of the whole area of the tube, and is thus subject to a retardation in phase which varies with the variation of the velocity of the liquid at different distances from the axes. It may be shown that the retardation in phase of the resultant disturbance when brought to a focus is equal to that which would be produced if the velocity of flow were uniform and equal to the mean velocity over the part of the tube occupied. If this were the whole tube the result of applying these corrections would be to increase the result given by Michelson and Morley for the convection coefficient from 0.434 to $0.5^{I} 5$. On the other hand, if the diameter of the beam were about 0.93 of the diameter of the tube the mean velocity would be so much greater that the convection-coefficient would be reduced to the theoretical value given by the formula of Lorentz, viz., $0.45 \mathrm{I}$. There is thus a possibility of general agreement, but the experiment is quite indecisive.

The announcement that Prof. Zeeman has repeated the experiments with great care and with monochromatic light and has succeeded in observing a dispersive effect is, therefore, of great importance, and his detailed results will be awaited with much interest (Amsterdam Proceedings, September 26).

E. Cunningham.

St. John's College, Cambridge, October 26.

\section{Flint Fracture.}

Mr. Lewis ABbotT's letter in NatuRe of October 22 is almost entirely irrelevant to the subject of my communication to NATURE of September 24. In this note I dealt solely with one form of flint fracture, viz., the large, flat, non-conchoidal fractures, surfaces which are produced by a certain type of "cleaving" blow, and pointed out how it is possible to determine the nature and direction of the fracturing-agent by the recognition of the fissures of varying size radiating from the point of impact. Mr. Abbott, however, states, these "are certainly not fissures"; but an examination of these markings upon a flint and a reference to the meaning of the word "fissure" in a dictionary will convince anyone that my description is correct.

The major part of Mr. Abbott's letter deals with subjects upon which my former note has no bearing, and though I agree that these are important and need investigation, yet it seems regrettable, if the problems they present were, as Mr. Abbott infers, in process of solution several years ago, that the knowledge already acquired at that time has not up to the present been laid before the scientific world. It is to be hoped that Mr. Abbott may be able to induce the collector who interviewed the late Sir John Evans to do so without delay.

I 2 St. Edmund's Road, Ipswich, October 23.

\section{TOWARDS NATURE-STUDY.1}

(x) P ROF. ABBOTT'S aim is to give " a simple statement of the fundamentals of General Biology," both for the general reader and the laboratory student. He deals with both plants and animals, shifting his field so as to get the best illustrations. The main subjects discussed are-living substance, the primary functions, metabolism, growth, differentiation, development, variation and heredity, organic response, species and their origin. The book is well-illustrated and marked by three other qualities-an admirable clearness which points to teaching experience, a pleasant freshness of treatment which is in part due to the numerous references to recent work, and an all-roundness of survey, for almost every aspect of biology is at any rate recognised and illustrated. This third quality lays the book open to the disadvantage of sometimes saying too little, but most introductory books of this sort say far too much. But we should have liked, for instance, to know more about those sea birds which "lay their eggs on the bare rocks and pay no more attention to them thereafter."

(2) Prof. J. R. Ainsworth-Davis is a firm believer in the value of "nature-study" as a factor in increasing efficiency, and his book-an outcome of large experience-is meant to indicate how the subject may be best dealt with, especially in country schools. After clearly indicating how arithmetic, for instance, may be made vital in the country schools by being applied to actual problems, he proceeds to show this is even more essential in connection with nature-study. For this reason the book gives prominence to common plants and animals and familiar physical phenomena. In regard to the part dealing with plants and animals, however, it appears to us that the author falls far short of his counsel, telling too much and suggesting too little. It is good pemmican, but it is pemmican. In his introduction he protests against the "informational obsession," and upholds "the educational ideal";

1 (1) "The Elementary Principles of General Biology." By Prof. J. F. A bott. Pp. xvit329. (New York: The Macmillan Co. London: Macmillan and Co., Ltd.. Igr4.) Price 6s. 6d.

(2) "The Pursuit of Natural Knowledge." By Prof. J. R. AinsworthDavic, Pp. iv. +234. (Cheltenham: Norman, Sawyer and Co., Lid.,

1914.) " Price Is. net. Animal Life by the Sea-shore. By Drs. G. A. and C.. L. Boulenger. 5s. net.

(4) " “The Naturalist at the Sea-shore." By R. Elmhirst. Pp. viii $+86+$ 8 plates. (London: A. and C. Black, I9r3.) Price is 6d. net.

(5) "Bird Studies in Twenty-four Lessons." By W. P. Westell. Pp. xii +r52. (Cambridge: University Press, 1914.) Price $2 s .6 d$. net.

(6) "Common British Beetles." By Rev. C A. Hall. Pp. vii+86. (f.ondon: A. and C. Black, r914.) "Price rs. $6 d$. net.

(7) "Odd Hours with Nature." By Alexander Urquhart. Pp. $323+$ plates. (London: T. Fisher Unwin, n.d.) Price 5s. net.

(8) Ernst Haeckel: "Die Natur als Künstlerin." Nebst : Dr. W. Breitenbach: "Formenschatz der Schöpfung." Pp. Ir4. (Berlin: Ch. Vita, Deutsrhes Verlaghaus, n.d.)

(9) "A Natural History of Bournemouth and District," including Archroology, Topngraphy, Municipal (iovernment, Climaie, Education Fauna, Flora and Geology. By the Members of the Bournemouth Natura Science Society. Edited by. Sir Daniel Morris. Pp. xiv-400. (Bournemouth : Natural Science Society, rgr4.) Price 2s. 6d. net.

(10) "Handbuch der n*turgeschichilichen Technik für Lehrer und Studierende der Naturwissenschaften." Herausgegeben von Prof. Bastian Schmid. Pp. viii +555. (Leipzig and Berlin: B. G. Teubner, 1914.) Price I 5 marks.

(i 1 " Biologen-Kalender." Edited by Prof. B. Schmid und Dr. r. Thesing. Errter Jahrgang. Pp. ix +5 r $_{3}$. (Leipzig and Berlin: B. G. Teubner, 1914). Price 7 marks.

NO. 2348, VOL. 94] 
but it seems to us that in the bulk of the book the author is informational with the best of them. But Prof. Ainsworth-Davis knows his own business, and while we do not think that his method (as regards living creatures) is the best, he has chosen it deliberately. We hasten, therefore, to say that he has produced a wonderful little book, clear, terse, and accurate, which will aid in their pursuit of natural knowledge those who combine good intellectual digestion with the inclination and opportunity to verify what they are told.

(3) It is interesting to find Drs. Boulenger, father and son, uniting their abilities and enthusiasm in the production of a guide to the study of the animal life of the seashore. The result is a delightful and effective book by which those interested can identify many of the littoral animals and get some trustworthy information about them. We confess to being surprised at the suggestion in the preface that there was a lack of a book of this kind, for Dr. Marion Newbigin's "Life by the Seashore" is an excellent and trustworthy guide, and Sinel's is also good. But there is no risk of exhausting the interest of the shore, and the book before us has a character of its own and pre-eminence in the excellence of its photographic illustrations, many of which are fascinatingly beautiful. That of the sea-horse (Fig. I) is a good instance.

The authors tell their story in a clear and interesting way, which stimulates both observation and reflection. We read of the wrasses sleeping on one side, of the stickleback's nest and large eggs, of the sting of the weever, of paternal care among pipe-fishes, of the homing of limpets, of the boring of piddocks, of the shrivelling of the lobster's muscles before moulting, of the colourchange in Hippolyte varians, of the various seashore insects, of the cotton-spinner's sticky thread-like tubes, of the partnership between hermit-crabs and anemones, and of much more that makes us long to be back to the shore again.

(4) Another shore-book, to be strongly recommended, has been written by Mr. Elmhirst, superintendent of the Marine Biological Station at Millport. It is the work of an experienced naturalist who has written simply and clearly about what he knows well. He begins with the common seaweeds and works up to the shore-birds, and by exercising a wise restraint has succeeded in giving a luminous, not over-crowded, picture of the natural history of the shore. He has many interesting notes on the habits of animals, telling us, for instance, of the way in which Echinus miliaris dresses itself up till it becomes "a sort of moving scrap-heap," of the shrimp's rapid burying of itself, of the sea-spider (Pycnogonum) sticking its proboscis into an anemone and sucking up the juices through a filter, of the dog-whelk boring through a mussel, and of the starfish slowly forcing the same bivalve to gape. There are some very effective photographs, but the most striking feature of the book is to be found in the charming coloured pictures by Mr. William Smith. It seems to us very unpractical to put one of these beautiful sketches on the cover. If it is put there it should also be repeated inside the book.

(5) Mr. Westell believes in "a very real desire for a school-book on birds," and he has suggested twenty-four practical out-of-door studies, which he has wisely arranged in the order of the seasons. The "lessons" are conversational and socratic, and they suffer a little from the defects of these qualities. The conversation is occasionally thin, and the questions are sometimes fatiguing. But there is a pleasant temper in the book and a feeling of the open-air. The children who answer all

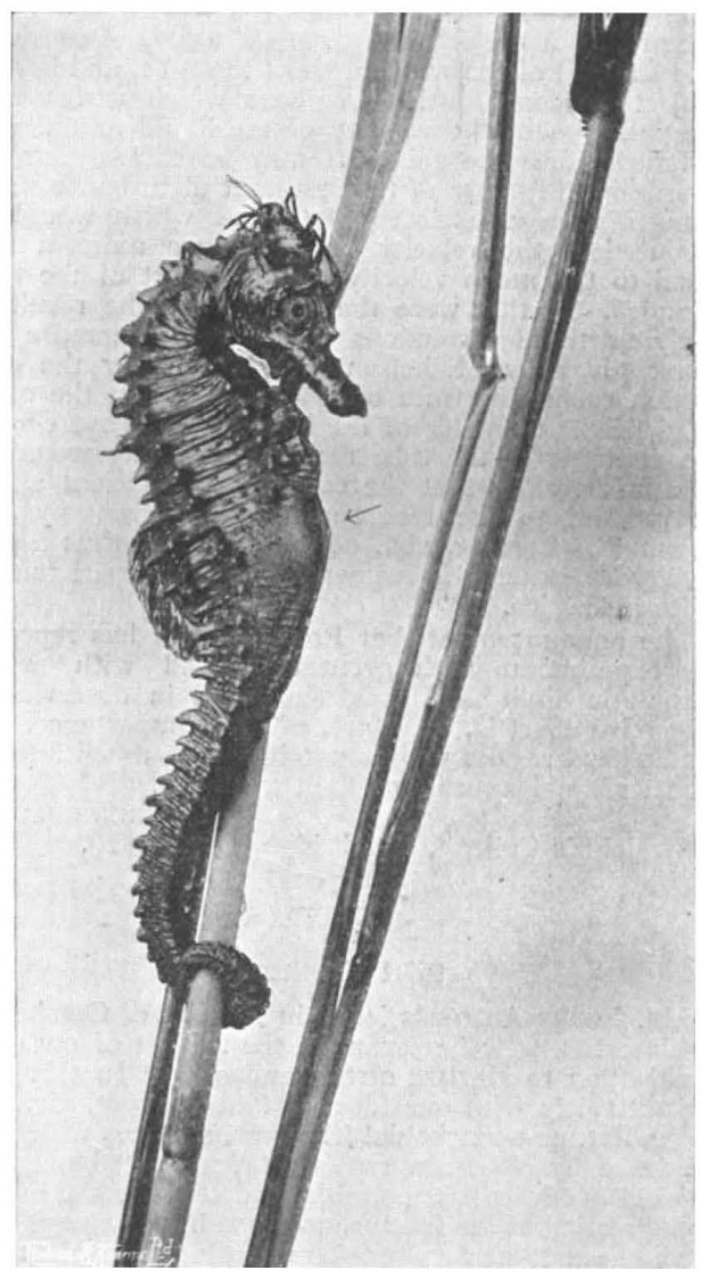

Fig. x. - Sea-horse. From "Animal Life by the Sea-shore."

the problems set-some of them very educativewill certainly know a lot about birds. We think that the author should have taken more care with his English-especially in a book intended for schools. Thus we read: "One of the most remarkable episodes connected with the life-story of these aquatic birds is the provision which has been made for the young to be able to take care of themselves as soon as they are born." As the starling "hawks and hovers in the air," etc., "it presents a fine study of a familiar bird which adds a good deal of charm to the bird life near at

NO. 2348, VOL. 94] 
home." It is a pity that there are many of these awkwardnesses in this little book. But the book is well-conceived and on the whole sound. It is very effectively illustrated, and the multiple appendix, mostly devoted to practical matters, from observational outfit to the Wild Birds' Protection Acts, will be found exceedingly useful.

(6) Mr. Hall has provided a useful introduction to the study of British beetles-a study which only needs to be begun seriously to become an enthusiasm. The book has an introductory chapter describing the external structure of beetles, and another on their habits, as illustrated by the Green Tiger beetle, the large water-beetle, the burying beetles, the cockchafer, and so on. Apart from some hints on collecting and mounting, the rest of the book is devoted to terse de- thing wrong. Holding this view, we have always a welcome for a book like Mr. Urquhart's "Odd Hours with Nature," which was evidently written with joy and sincerity. The author takes us with him on his every week walks, and we enjoy his company as he shows us the tree-creeper in the winter-woods, the supernumeraries (bachelors and widows?) of the rookery, the field where the hares fight, the trickery of the lapwing, the trustfulness of the young deer, the dipper walking on the bottom of the stream, and so on till we come back to a queen humble-bee disturbed in her winter retreat. There is nothing very profound in the author's studies, but they are the fruits of observation and reflection, written in excellent style, expressing a love of nature and contributing to its diffusion. We give an example

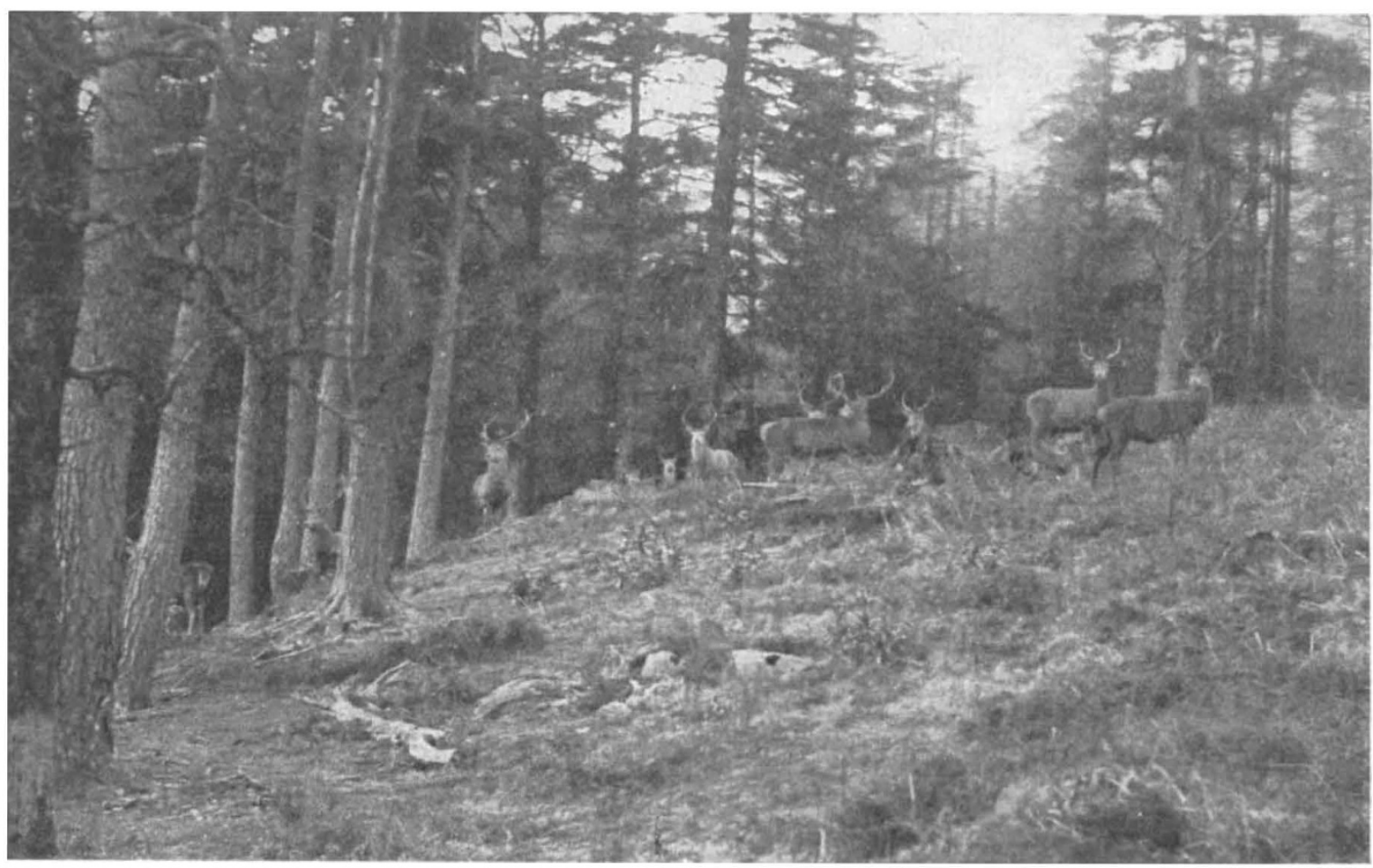

FIG. 2.-In Stag Ground. From "Odd Hours with Nature.'

scriptions of some of the commoner forms. These descriptions are quite effective, but we should like to have had more information in regard to habits. The coloured plates, which are on the whole very successful, will be of great service in identification. It seems to us very unpractical to put one of the plates on the cover. There are some interesting photographs, but that of the trachea of Dytiscus does not show the structure as it professes to do. We wish the book success.

(7) There is an inteilectual discipline in nature study and the possibility of learning certain lessons which are for our good as citizens of the world, but perhaps the surest gain is simply an increase in our love for the country. If nature study does not lead towards this, there is some-
(Fig. 2) of the well-chosen illustrations with which the studies are adorned.

(8) It is said that many people have been led by the pathway of photography to an appreciation of the beauty of the world, and the book of striking photographs of natural objects which has been published by the director of the "Urania" institute in Berlin should prove effective in this direction. It is a scientific picture-book, displaying some of the most beautiful objects in the world, many of which will be new and startling to most people. The album illustrates the exuberant decorativeness of Haeckel's Radiolarians, Medusæ, and Siphonophores; the gracefulness of Allman's zoophytes; the futurism of Lehmann's fluid crystals; the fascinating NO. 2348, voL. 94] 
beauty of calla-lilies, heaths, poppies, and ferns; the likeness between frost-flowers on the windowpane and the snow-laden forest-trees; the flowerlike corals; the individuality of shells; the exquisiteness of hidden organic architecture; the conscious beauty of Argus pheasant and bird of paradise; and much more besides. Who is sufficient for all these things? The pages are too crowded to do full justice to the various pictures, the table of the beauty-feast is overloaded, but no one can fail to get an impression of subtle and exuberant beauty. The text accompanying the album consists of two essays. The first is by Haeckel, entitled, "Nature as Artist," and in it the veteran expounds his theory of a " plastic instinct" in protoplasm. Every organic product arises in accordance with physical and chemical laws, but it is none the less an expression of the "cell-soul." Many naturalists have said the same thing in different words! The second essay is by Dr. W. Breitenbach and deals with the universality of beauty in nature, its manifold expression, and the enrichment of human life which it may afford.

(9) We have nothing but praise for the Regional Survey which has been compiled and published by the Bournemouth Natural Science Society under the able editorship of Sir Daniel Morris. It is a model of what such a book should be-dealing with the topography, geology, zoology, and botany of the district, and not forgetting the works of man, both past and present. The society is to be congratulated on having so many members able to co-operate competently in a work of this kind; and those who have the good fortune to reside in an area with so many interesting features are to be congratulated on the possession of this excellent aid to a fuller appreciation of their opportunities.

(10) Prof. Bastian Schmid has done a usefu1 piece of work in compiling a manual on the technique of natural science, and he deserves our thanks. The book had, of course, to be written co-operatively, for only experts could deal effectively with the great variety of technical methods now in use in nature study in the wide sense. Prof. H. Poll deals with zoological microscopy, Dr. H. Fischer with botanical microscopy, including bacteriological and mycological methods, Prof. P. Claussen with experiments in vegetable physiology, Prof. R. Rosemann with methods in animal physiology, Dr. C. Wagler with hydrobiology, Dr. O. Steche with collecting and preserving insects, Dr. Paul Kammerer with collecting molluscs and vertebrates, Prof. Schoeler with herbaria, Prof. B. Wandolleck with preserving animals and setting them up, Prof. F. Urban with vivaria, Dr. P. Esser with school-gardens, Dr. H. Fischer with the microscope, Prof. B. Wandolleck with photography, Prof. R. Fricke with excursions, the editor with practical arrangements and devices in schools and colleges, Dr. A. Berg with geological school-collections, and Prof. Bock with the care and appreciation of what is beautiful and instructive in open nature. The result of this collaboration is a very remarkable NO. 2348, VOL. 94] and valuable book which ought to be utilised by those teachers of natural science who wish to make their instruction more effective. Where we have been able to test the work, we have found it to be altogether to the point-detailed, precise, and up to date.

(I I) Drs. B. Schmid and C. Thesing have made a brave attempt to combine a Who's Who in Biology, a directory of institutes, gardens, and technicians, an obituary, a list of the most important recent biological publications, and a number of short essays dealing with present-day problems. It is the first issue, and we sympathise with the editorial appeal for suggestions rather than criticisms. We would suggest that the editors should re-cast their net. A list of contemporary biologists which omits Bateson, Delage, Wilson (to take an instance from each of three countries), obviously requires revision, and the same remark applies to the pages devoted to the almost impossible task of giving a list of the most important publications. The bibliographies of the works of not a few of the biologists are much in need of pruning: others, such as Sir Ray. Lankester's, are as much in need of being brought nearer completeness. The introductory essays on bird-marking, symbiosis, phenology, natural science in schools, problems of modern zoology, microscopic technique, and the like are admirable. As the calendar makes for co-ordination, we wish it success.

\section{THE TOTAL SOLAR ECLIPSE OF $A U G U S T$ 2I, I9I4.}

(i) The Royal Observatory Eclipse Expedition to Minsk, Russia.

THE programme of observations of the Royal Observatory Eclipse Expedition to Minsk, Russia, was in the main the same as that planned for the Brazilian eclipse in I9r2, but which rain had prevented from being carried out. The instruments comprised:(I) the Thompson coronagraph, consisting of a lens of 9 in. aperture and of $8 \mathrm{ft}$. 6 in. focal length, in conjunction with a Dallmeyer negative enlarger, giving an equivalent focal length of $36 \mathrm{ft}$., for the purpose of taking large-scale photographs of the corona, on a scale of 4 in. to the sun's diameter. (2) Two telescopes of 6 in. aperture, and of focal lengths $2 \mathrm{ft} .3 \mathrm{in}$., and $6 \mathrm{ft} .6 \mathrm{in}$. respectively, used in conjunction with green colour filters (Wratten and Wainwright's mercury monochromat), which let through a band in the green in the region of the coronium line $\lambda 530_{3}$, the object of these being to obtain evidence as to the presence and distribution of coronium in the corona. In order to disperse such continuous light from the corona as the filter transmitted, a prism was placed before each object glass. (3) The Hills' quartz spectrograph for obtaining the ultra-violet spectrum of the flash and of the corona. For (r) and (2) I6 in. cœlostats were used, and for (3) a cœlostat with a 9-in. speculum mirror, in combination with a speculum condensing mirror. Provision was also made for obtaining iron arc 